\title{
XPD and hOGG1 gene polymorphisms in reperfusion oxidative stress
}

\author{
O. İsbir ${ }^{1}$, U. Görmüş ${ }^{2}$ H.A. Ergen ${ }^{3}$, B. Çakmakoğlu ${ }^{3}$, Ö.T. Kahraman ${ }^{3}$ \\ and N. Baykan ${ }^{1}$ \\ ${ }^{1}$ Department of Anesthesiology and Reanimation, \\ Faculty of Medicine, Acibadem University, Istanbul, Turkey \\ ${ }^{2}$ Department of Biochemistry, Faculty of Medicine, \\ Istanbul Bilim University, Istanbul, Turkey \\ ${ }^{3}$ Department of Molecular Medicine, Institute for Experimental Medicine, \\ Istanbul University, Istanbul, Turkey \\ Corresponding author: O. İsbir \\ E-mail: olcayisbir@yahoo.com
}

Genet. Mol. Res. 10 (4): 3157-3162 (2011)

Received March 2, 2011

Accepted October 7, 2011

Published December 19, 2011

DOI http://dx.doi.org/10.4238/2011.December.19.4

\begin{abstract}
Knee replacement surgery is an ischemia/reperfusion model, as it uses tourniquet applied to the knee area to stop the blood flow during the operation. Fifty patients that were undergoing elective arthroscopic knee surgery were included in our study. Human 8-oxoguanine glycosylase 1 (hOGG1) is an enzyme to repair specific DNA lesions and a good marker of hydroxyl radical damage to DNA. XPD is another DNA repair gene. We investigated the effect of hOGG1 (Ser326Cys) and XPD (Lys751Gln) polymorphisms on the oxidative stress level after reperfusion. To evaluate oxidative stress conditions, we measured 8-hydroxyguanosine and malondialdehyde (MDA) levels. Polymorphism analyses were done by PCR-RFLP; serum 8-hydroxyguanosine and MDA levels were determined by enzyme-linked immunoassay. There were no significant differences between serum MDA and 8-hydroxyguanosine levels in the samples taken before and after tourniquet application; none of these parameters were related with hOGG1 genotypes. However, we
\end{abstract}


observed increased MDA levels after tourniquet application in $\mathrm{M}$ allele carriers for the XPD gene; this could mean that M allele carriers are more prone to DNA damage due to oxidative activity.

Key words: Oxidative stress; XPD; hOGG1; Polymorphisms

\section{INTRODUCTION}

The metabolic effects of ischemia on skeletal muscle tissue have been extensively described in animal studies (Westman et al., 2007). Unfortunately, the underlying mechanisms are not yet understood. One model of ischemia/reperfusion conditions to be studied in humans can be knee replacement surgery, because in this case, a tourniquet is applied on the knee area to stop the blood flow through the area during the operation (Westman et al., 2007; de Groot et al., 2010). Such orthopedic surgeries are thought to be good models to evaluate the production of antioxidants and for testing antioxidant effects of anesthetic agents. In knee replacement surgery, tourniquet application has been shown to induce ischemia, anaerobic metabolism and oxidative stress, increasing the production of ROS (reactive oxygen species) (Westman et al., 2007).

Reactive oxygen species are known to attack nucleic acids and their related compounds, generating various modified nucleobases that seem to play pivotal roles in mutagenesis, and 7,8-dihydro-8-oxoguanine $(8-\mathrm{OHdG})$ is one of the most abundant among these modified nucleobases (Cheng et al., 1992; Weiss et al., 2005). It is a highly mutagenic change that can occur as a consequence of the oxidation process, and the protein product of this change is frequently used to determine the level of oxidative stress (Wu et al., 2004). Human 8 -oxoguanine glycosylase 1 (hOGG1) is the enzyme that repairs 8-OHdG lesions by excising 8-hydroxyguanine from damaged DNA, and it is a good marker of hydroxyl radical damage to DNA (Kohno et al., 1998; Weiss et al., 2005). The hOGG1 gene (hOGG1) is located on chromosome 3p26.2 (Weiss et al., 2005). A polymorphism of hOGG1, a guanine-to-cytosine substitution in exon 7, that causes a serine (Ser) to cysteine (Cys) amino acid change at codon 326 (Ser326Cys), has been thought to be a functional polymorphism (Vodicka et al., 2007; Yuan et al., 2010). Oxidative stress is known to cause degenerations in vital cellular components such as lipids and proteins, besides DNA, increase malondialdehyde (MDA) levels and decrease reduced glutathione activity (Goyal and Anil, 2007). MDA is a decomposition product of oxidized lipids, or it can be formed by the reaction between acrolein and hydroxyl radicals; it is a valid biomarker of oxidative stress (Lykkesfeldt, 2007).

In this study, we aimed to investigate the effect of hOGG1 (Ser326Cys) and XPD (Lys751Gln) polymorphisms on the oxidative stress levels after reperfusion by measuring serum concentrations of 8-hydroxyguanosine and MDA as oxidative stress markers.

\section{MATERIAL AND METHODS}

\section{Patients}

After obtaining approval to conduct the study from the local ethics committee and written informed consent from each patient, demographic data were collected prospectively. The patients selected for this study were $18-60$ years old $(\mathrm{N}=50)$ with ASA physical status 
I-II, undergoing elective arthroscopic knee surgery with a pneumatic tourniquet time of 3045 min (Table 1). Patients taking antioxidant drugs or those with metabolic, renal or hepatic disturbances were excluded from the study.

\section{Anesthetic management}

All operations were performed by senior surgeons and two senior residents. The surgical team and the anesthesiologist, who were responsible for the postoperative case of the patients, were blinded to the presence or absence of the hOGG1 (Ser326Cys) gene.

All patients were premedicated with $0.5 \mathrm{mg}$ oral alprazolam $45 \mathrm{~min}$ before surgery. Heart rate (HR), non-invasive blood pressure (NIBP), peripheral oxygen saturation $\left(\mathrm{SpO}_{2}\right)$, and end-tidal partial pressure of carbon dioxide $\left(\mathrm{EtCO}_{2}\right)$ were monitored in the operating room. Anesthesia was induced with $2 \mathrm{mg} / \mathrm{kg}$ propofol and $0.5 \mathrm{mg} / \mathrm{kg}$ rocuronium bromide. Laryngeal mask airways were inserted after preoxygenation with $100 \%$ oxygen. Lungs were ventilated at a tidal volume of $10 \mathrm{~mL} / \mathrm{kg}$ at a rate of 12 breaths per minute. Anesthesia was maintained with $1 \%$ sevoflurane and $30 \% \mathrm{~N}_{2} \mathrm{O}$ carried in oxygen. Remifentanil, 0.25 $\mu \mathrm{g} \cdot \mathrm{kg}^{-1} \cdot \mathrm{h}^{-1}$, was started as soon as propofol was applied. The pneumatic tourniquet was inflated after the exsanguination of the limb and the pressure was kept between 300-350 $\mathrm{mmHg}$ throughout the surgery.

Venous blood samples of 50 men were collected before and after tourniquet. The antecubital vein of the left arm was used to collect the baseline venous samples before tourniquet application during the intravenous line placement. Second venous samples were taken from the antecubital vein of the contralateral arm $10 \mathrm{~min}$ after the deflation of the tourniquet.

At the end of the surgery, all patients were extubated after reversal of neuromuscular blockade with $0.01 \mathrm{mg} / \mathrm{kg}$ atropine and $0.05 \mathrm{mg} / \mathrm{kg}$ neostigmine.

\section{DNA isolation and genotyping}

Genomic DNA was extracted from isolated lymphocytes by a standard salting out procedure (Miller et al., 1988). The extracted DNA was used for characterization of the following polymorphic DNA repair genes. Polymerase chain reaction (PCR) followed by restriction fragment length polymorphism (RFLP) was used for genotyping (Wood et al., 2001).

The hOGG1 (Ser326Cys) polymorphism, a $\mathrm{C} \rightarrow \mathrm{G}$ transversion in exon 7 was determined using the primers (forward) 5'-ACTGTCACTAGTCTCACCAG-3' and (reverse) 5'-GGAAGGTGCTTGGGGAAT-3'. The PCR conditions consisted of an initial denaturation step at $95^{\circ} \mathrm{C}$ for $2 \mathrm{~min}$, followed by 35 cycles of $95^{\circ} \mathrm{C}$ for $1 \mathrm{~min}, 60^{\circ} \mathrm{C}$ for $1 \mathrm{~min}$ and $75^{\circ} \mathrm{C}$ for $1 \mathrm{~min}$, and a final extension step at $72^{\circ} \mathrm{C}$ for $5 \mathrm{~min}$. The 200 -bp PCR product was digested with Fnu4HI. Genotypes were determined for the polymorphism as Ser/Ser (200 bp), Ser/Cys (100, 200 bp), or Cys/Cys (100 bp).

The XPD Lys751Gln polymorphism, an $\mathrm{A} \rightarrow \mathrm{C}$ transversion in exon 23 (position 35931), was determined using the primers (forward) 5'-CCTCTCCCTTTCCTCTGTTC-3' and (reverse) 5'-CAGGTGAGGGGGGACATCT-3'. The PCR conditions consisted of an initial denaturation step at $95^{\circ} \mathrm{C}$ for $2 \mathrm{~min}$, followed by 35 cycles of $94^{\circ} \mathrm{C}$ for $1 \mathrm{~min}, 52^{\circ} \mathrm{C}$ for $1 \mathrm{~min}$ and $72^{\circ} \mathrm{C}$ for 1 $\mathrm{min}$, and a final extension step at $72^{\circ} \mathrm{C}$ for $5 \mathrm{~min}$. The 734-bp PCR product was digested with PstI; the Gln allele was cut into 646- and 88-bp fragments (Lys allele not digested) (Yeh et al., 2005). 


\section{Determination of serum 8-hydroxyguanosine levels}

Whole blood samples were centrifuged at $1500 \mathrm{~g}$ for $10 \mathrm{~min}$ at room temperature and serum was immediately removed and frozen at $-20^{\circ} \mathrm{C}$ until serum 8 -hydroxyguanosine levels were determined by enzyme-linked immunoassay (Cell Biolabs Inc., CA, USA).

\section{Determination of serum MDA levels}

Blood samples were centrifuged for $10 \mathrm{~min}$ at $1500 \mathrm{~g}$ at room temperature and serum was immediately removed and frozen at $-20^{\circ} \mathrm{C}$ until serum MDA levels were determined by enzyme-linked immunoassay.

\section{Statistical analysis}

The statistical analyses were performed using the SPSS 11.0 statistical software package (SPSS, Chicago, IL, USA). P values less than 0.05 were considered to be statistically significant. Also, linear regression analysis was used to investigate genotype and DNA damage association. The Student $t$-test was used to investigate the serum MDA levels between the genotypes. Allele frequencies were found using the gene counting technique. To determine the relative risks, odds ratios and $95 \%$ confidence intervals were used.

\section{RESULTS}

Demographic characteristics are summarized in Table 1.

Table 1. Clinical characteristics, duration of tourniquet and anesthesia in patients undergoing knee surgery.

\begin{tabular}{lc}
\hline Characterıstıc & Patıents $(\mathrm{N}=50)$ \\
\hline Age (years) & $50(20-80)$ \\
Gender (female/male, N) & $22 / 29$ \\
Shivering (\%) & $7.8 \%$ \\
Nausea (\%) & $2 \%$ \\
Duration of tourniquet application (min) & $41(15-149)$ \\
Duration of anesthesia application (min) & $60(25-160)$ \\
\hline
\end{tabular}

"Values are reported as median (interquartile range).

There was no significant difference between serum MDA $(\mathrm{P}>0.877)$ and 8-hydroxyguanosine $(\mathrm{P}>0.195)$ levels in the samples taken before and after tourniquet application (Table 2).

Table 2. MDA and 8-hydroxyguanosine levels before and after the tourniquet application.
\begin{tabular}{lcc}
\hline & MDA $(\mathrm{pmol} / \mathrm{mg})$ & 8-Hydroxyguanosine $(\mathrm{pmol} / \mathrm{mg})$ \\
\hline Before tourniquet $(m e a n \pm \mathrm{SD})$ & $35.56 \pm 9.20$ & $8.60 \pm 10.66$ \\
After tourniquet $($ mean $\pm \mathrm{SD})$ & $35.82 \pm 9.50$ & $12.14 \pm 11.84$ \\
\hline
\end{tabular}

The associations between genotypes, alleles and MDA and 8-hydroxyguanosine levels are shown in Table 3. We did not find any relationship between hOGG1 genotypes and serum leves of MDA and 8-hydroxyguanosine. With regard to XPD genotypes and alleles, we ob- 
served an increase in MDA levels after tourniquet application in the $\mathrm{M}$ allele $(\mathrm{P}<0.046$, $95 \% \mathrm{Cl}=0.142-13.600)$ and an almost significant decrease in wild-type LL genotype patients after tourniquet application $(\mathrm{P}<0.056,95 \% \mathrm{Cl}=0.190-13.650$; Table 3$)$.

\begin{tabular}{|c|c|c|c|}
\hline XPD genotype (N) & MDA levels before the operation (pmol/mg) & MDA levels after the operation (pmol/mg) & P values \\
\hline MM (3) & $21.33 \pm 17.50$ & $30.66 \pm 4.5$ & $>0.05$ \\
\hline LM (20) & $36.68 \pm 9.17$ & $39.21 \pm 8.44$ & $>0.05$ \\
\hline LL (18) & $36.68 \pm 5.81$ & $33.26 \pm 10.19$ & $0.056^{*}$ \\
\hline $\mathrm{M}+(23)$ & $34.59 \pm 11.41$ & $38.04 \pm 8.48$ & $0.046^{* *}$ \\
\hline $\mathrm{L}+(38)$ & $36.68 \pm 7.57$ & $36.23 \pm 9.71$ & $>0.05$ \\
\hline hOOG1 genotypes & $\begin{array}{l}\text { 8-Hydroxyguanosine levels before } \\
\text { the operation }(\mathrm{pmol} / \mathrm{mg})\end{array}$ & $\begin{array}{l}\text { 8-Hydroxyguanosine levels after } \\
\text { the operation }(\mathrm{pmol} / \mathrm{mg})\end{array}$ & \\
\hline$\overline{\operatorname{Ser} / \operatorname{Ser}(\mathrm{n}: 39)}$ & $236.51 \pm 423.15$ & $239.43 \pm 421.58$ & $>0.05$ \\
\hline Ser/Cys (n:12) & $93.25 \pm 285.61$ & $95.83 \pm 284.72$ & $>0.05$ \\
\hline Cys/Cys (n:0) & 0 & 0 & \\
\hline
\end{tabular}

\section{DISCUSSION}

In orthopedic surgeries, tourniquets are commonly applied to reduce blood loss and obtain a clearer surgical field; this makes it easier to develop scientific projects in the area of ischemia-reperfusion injuries. Because of DNA damage, ROS activity on membrane lipids produces peroxides such as MDA, which has been used as a marker of lipid peroxidation (Del Rio et al., 2005). In our study, we had such patients undergoing elective arthroscopic knee surgery; our aim was to investigate the changes in MDA levels before and after the tourniquet application, and we found no difference in these levels in the total patient population. Despite our results, it was previously found that ROS and MDA levels increased in the reperfusion stage after ischemia (Cheng et al., 2003; Westman et al., 2007; Lykkesfeldt, 2007). The tourniquet application durations and the times of sample collection usually differed in previous studies; there was no suggested standard duration for these applications, but the duration of the ischemic period was also found to be important in reperfusion injury (Homer-Vanniasinkam et al., 2001; Kloner and Jennings, 2001; Cheng et al., 2003). Thus, our results may differ because of such differences.

We observed an increase of MDA levels after tourniquet application in $\mathrm{M}$ allele carriers for the XPD gene, and contrarily, there was an almost significant decrease in LL genotype patients. This may indicate that $\mathrm{M}$ allele carriers for the XPD gene are much more prone to DNA damages because of oxidative damage. However, in order to correlate such parameters, we had to consider also the effects of anesthetic agents or other medications on the oxidative damage. There have been several studies about alprazolam, propofol and $\mathrm{N}$-acetylcysteine, and it was previously shown that alprazolam is an effective agent in ameliorating alterations in oxidative stress and attenuating malondialdehyde levels (Goyal and Anil, 2007). Propofol was also shown to have antioxidant activity against lipid peroxidation (Murphy et al., 1993; Aldemir et al., 2001).

We did not find any significant difference in 8-hydroxyguanosine levels before and after tourniquet application. Although the polymorphism causing serine (Ser) to cysteine (Cys) amino acid change at codon 326 (Ser326Cys) was thought to be functional in some previous 
studies (Vodicka et al., 2007; Yuan et al., 2010), we could not find such difference in our study. Rather, our findings are in line with those of Kohno et al. (1998).

Our study is a rare one containing several parameters altogether, so in case of enlarging the study group, there will be more obvious results to contribute to the understanding of the molecular basis of reperfusion conditions.

\section{REFERENCES}

Aldemir O, Celebi H, Cevik C and Duzgun E (2001). The effects of propofol or halothane on free radical production after tourniquet induced ischaemia-reperfusion injury during knee arthroplasty. Acta Anaesthesiol. Scand. 45: 1221-1225.

Cheng KC, Cahill DS, Kasai H, Nishimura S, et al. (1992). 8-Hydroxyguanine, an abundant form of oxidative DNA damage, causes $\mathrm{G} \rightarrow \mathrm{T}$ and $\mathrm{A} \rightarrow \mathrm{C}$ substitutions. J. Biol. Chem. 267: 166-172.

Cheng YJ, Chien CT and Chen CF (2003). Oxidative stress in bilateral total knee replacement, under ischaemic tourniquet. J. Bone Joint Surg. Br. 85: 679-682.

de Groot PC, Thijssen DH, Sanchez M, Ellenkamp R, et al. (2010). Ischemic preconditioning improves maximal performance in humans. Eur. J. Appl. Physiol. 108: 141-146.

Del Rio D, Stewart AJ and Pellegrini N (2005). A review of recent studies on malondialdehyde as toxic molecule and biological marker of oxidative stress. Nutr. Metab. Cardiovasc. Dis. 15: 316-328.

Goyal R and Anil K (2007). Protective effect of alprazolam in acute immobilization stress-induced certain behavioral and biochemical alterations in mice. Pharmacol. Rep. 59: 284-290.

Homer-Vanniasinkam S, Rowlands TE, Hardy SC and Gough MJ (2001). Skeletal muscle ischaemia-reperfusion injury: further characterisation of a rodent model. Eur. J. Vasc. Endovasc. Surg. 22: 523-527.

Kloner RA and Jennings RB (2001). Consequences of brief ischemia: stunning, preconditioning, and their clinical implications: part 1. Circulation 104: 2981-2989.

Kohno T, Shinmura K, Tosaka M, Tani M, et al. (1998). Genetic polymorphisms and alternative splicing of the hOGG1 gene, that is involved in the repair of 8-hydroxyguanine in damaged DNA. Oncogene 16: 3219-3225.

Lykkesfeldt J (2007). Malondialdehyde as biomarker of oxidative damage to lipids caused by smoking. Clin. Chim. Acta 380: 50-58.

Miller SA, Dykes DD and Polesky HF (1988). A simple salting out procedure for extracting DNA from human nucleated cells. Nucleic Acids Res. 16: 1215.

Murphy PG, Bennett JR, Myers DS, Davies MJ, et al. (1993). The effect of propofol anaesthesia on free radical-induced lipid peroxidation in rat liver microsomes. Eur. J. Anaesthesiol. 10: 261-266.

Vodicka P, Stetina R, Polakova V, Tulupova E, et al. (2007). Association of DNA repair polymorphisms with DNA repair functional outcomes in healthy human subjects. Carcinogenesis 28: 657-664.

Weiss JM, Goode EL, Ladiges WC and Ulrich CM (2005). Polymorphic variation in hOGG1 and risk of cancer: a review of the functional and epidemiologic literature. Mol. Carcinog. 42: 127-141.

Westman B, Weidenhielm L, Rooyackers O, Fredriksson K, et al. (2007). Knee replacement surgery as a human clinical model of the effects of ischaemia/reperfusion upon skeletal muscle. Clin. Sci. 113: 313-318.

Wood RD, Mitchell M, Sgouros J and Lindahl T (2001). Human DNA repair genes. Science 291: 1284-1289.

Wu LL, Chiou CC, Chang PY and Wu JT (2004). Urinary 8-OHdG: a marker of oxidative stress to DNA and a risk factor for cancer, atherosclerosis and diabetics. Clin. Chim. Acta 339: 1-9.

Yeh CC, Sung FC, Tang R, Chang-Chieh CR, et al. (2005). Polymorphisms of the XRCC1, XRCC3, \& XPD genes, and colorectal cancer risk: a case-control study in Taiwan. BMC Cancer 5: 12.

Yuan W, Xu L, Feng Y, Yang Y, et al. (2010). The hOGG1 Ser326Cys polymorphism and breast cancer risk: a metaanalysis. Breast Cancer Res. Treat. 122: 835-842. 